\title{
Attitude intérieure de la prière et orientation intérieure phénoménologique, (27.11.1931), Husserliana, Appendice XXV
}

\author{
Traducteur : Claudia Serban et Natalie Depraz
}

\section{OpenEdition}

\section{Journals}

Édition électronique

URL : https://journals.openedition.org/alter/2205

DOI : $10.4000 /$ alter.2205

ISSN : 2558-7927

\section{Éditeur :}

Association ALTER, Archives Husserl (CNRS-UMR 8547)

\section{Édition imprimée}

Date de publication : 1 novembre 2020

Pagination : 297-298

ISBN : 978-2-9550449-6-4

ISSN : 1249-8947

Référence électronique

"Attitude intérieure de la prière et orientation intérieure phénoménologique, (27.11.1931), Husserliana, Appendice XXV », Alter [En ligne], 28 | 2020, mis en ligne le 22 décembre 2020, consulté le 12 décembre 2021. URL : http://journals.openedition.org/alter/2205; DOI : https://doi.org/10.4000/alter 2205

Ce document a été généré automatiquement le 12 décembre 2021.

Revue Alter 


\section{Attitude intérieure de la prière et orientation intérieure phénoménologique, (27.11.1931), Husserliana, Appendice XXV \\ Traduction : Claudia Serban et Natalie Depraz}

Les instincts au sens courant, les pressentiments originaires « instinctifs », comme l'être intérieur originaire de Dieu, non-intuitif et de l'ordre du pressentiment, qui est au fondement de toute religion effective. À ce propos, on doit surtout prendre en compte ceci : dans la prière effectivement intérieure, dans la prière véritable, le Je qui prie n'est pas orienté vers l'extérieur mais vers l'intérieur. Toutes les images cultuelles sont des images, et pourtant elles ne sont pas tout à fait des images : car déjà lorsque Dieu est rendu dans la représentation de manière mondaine et réale comme "Père ", avec la structure d'un père effectif, Dieu n'est plus présent en tant que Dieu. Une image doit pourtant entretenir une véritable analogie avec ce qu'elle met en image, il doit y avoir là l'identité d'une forme essentielle. C'est naturellement un grand problème - dont la solution relève de l'achèvement de la philosophie - que de rendre intelligible quel type de "symbolisation" a lieu dans les symboles religieux et, si elle implique une ressemblance, dans quelle direction celle-ci opère. Toute image de Dieu dirige le regard vers l'extérieur ; or la relation effective et actuelle à Dieu est intérieure : c'est l'attitude intérieure de la prière. Dans chaque instinct inentamé, lorsqu'il est in actu, l'orientation intentionnelle est là, mais avec un horizon vide qui n'est pas du tout formé, <orientée vers> un but qui n'a aucune structure de familiarité pré-dessinée. C'est ce qui est commun à la conscience religieuse et à l'instinct. Mais doit-on dire dès lors que seule la philosophie produit la clarté sur ce qui, dans la conversion intérieure de la prière, s'annonce dans l'intériorité elle-même ? Ou bien cela se passe-t-il ici comme pour tous les instincts, qui se remplissent certes et pré-dessinent leurs buts à travers le remplissement - de sorte que ce devenir-patent est seulement relatif, de sorte que ce qui est déjà patent pré-dessine à nouveau, dans une cohésion plus élargie, quelque chose de plus pour le rendre ensuite patent, alors que la philosophie universelle est en toutes choses celle qui, dans la forme la plus haute de l'activité philosophique- 
phénoménologique, [247] rend patent ce qui est vrai au sens ultime, à savoir l'univers de la relativité dans sa formation de sens infinie ? L'orientation intérieure de la religion ou de la personne qui prie - en tant qu'elle trouve Dieu en le cherchant - et de la communauté de prière - en tant qu'elle fait cela à l'unisson, donc de manière communautaire en communion avec Dieu - ne signifie pas, comme ces mots l'indiquent déjà, une orientation vers l'intérieur entendu comme ma vie privée. Cette orientation intérieure est parallèle à l'orientation intérieure phénoménologique en laquelle, en traversant mon intériorité, le chemin passe dans tous les autres (en tant qu'autres intérieurs, et non pas en tant qu'êtres humains extérieurs ayant une réalité spatiotemporelle), et ce n'est que par là que ce chemin donne sur le monde et sur l'existence humaine propre et étrangère. 